\title{
Frequency and Voltage Stability Assessment Applied to Load Shedding
}

\author{
K.Reddy Gayathri ${ }^{1}$, G.V.Maruteswar ${ }^{2}$ \\ Power System, Electrical And Electronics Engineering, Sv University, \\ Tirupati, Andra Pradesh, India.
}

\begin{abstract}
Under voltage load shedding (UVLS) and under frequency load shedding (UFLS) is plays vital role in the power system operation. As large disturbances are occur frequently in previous days. Generally these two methods are work independently from each other, and are not designed to integrated way to use their combined effect on load shedding. The reactive power hardly consider in load shedding process. To fill this gap, we froth put in this paper a new concentration about adaptive load shedding algorithm. The phasor measurement unit can gives both voltage and frequency information. The main concept of the new method is consideration of reactive power combined with active power in load shedding strategy. This method is gives information about the combined voltage and frequency stability issues is better than the independent approaches. The new method is tested on the IEEE 39-Bus system, in order to compare with other methods. By applying this new method to the system, that system will be back to new stable steady state that is better from the perspective of voltage and frequency and loadability.
\end{abstract}

Index terms- Adaptive load shedding methods, under voltage load shedding, under frequency load shedding, synchrophasor, power system stability, phasor measurement unit (PMUs).

\section{I.INTRODUCTION}

Mostly as a consequence of without proper operation of electricity markets and growing power consumption, the power systems are often operated with their some stability limits.

In case of huge disturbances such as generators tripping and faults on transmission lines leading to cascading faults [1]. Due to this active and reactive power imbalance can finally lead to simultaneous large frequency and voltage instability, if increases active and reactive power imbalance the system will be collapse.

However, the load shedding schemes are UFLS and UVLS are designed independently and they establish the last line of protect against frequency and voltage stabilities [2], [3].The action of UFLS usually consider the only frequency information it may have unanticipated. A similar issue affects the conventional UVLS only local voltage magnitude. For improving the conventional load shedding schemes adaptive UFLS was introduced. In this process still only frequency is used. The voltage independent modeling is considering for the active power estimation furthermore some authors suggested combinational load shedding methods based on UFLS [4],[6]. In which the distribution of load shedding is determined using the voltage magnitude information.

With diffusion of wide-area monitoring and control system (WAMCS) [9] based on a PMUs can provided synchronize measurement which in the included the magnitude and phase angle voltage and currents and rate of change of frequency [12]. In this paper the synchrophasor measurement are used to more advanced adaptive load shedding on the bases both the frequency and voltage stability indies. In the canonical method for distribution of load shedding the incipient load of each bus is considering as start point for allocation.

Hence all load buses are involving sharing the total power imbalance without selection [10], [14]. According to the knowledge authors power flow tracing is a reasonable choice for the selection of a subset of all load buses in the load shedding distribution for general use. In load shedding scheme power flow tracking is proposed for fault for originating from lines tripping. We consider the case of generators tripping by means of flow tracing we can accurately determine the corresponding proportional power of each load buses at the supplied by the last generators or lines.

In this paper we propose a innovative load shedding methods that consider frequency and voltage stability assessment simultaneously such adaptive method is organized in three main steps:

1) Determination of trigger for activating the load shedding procedure.

2) Estimation of total power imbalance for the whole system.

3) Distribution of the total power imbalance to individual load bus. 
In first step, global voltage stability indices and the frequency information for the equivalent inertial center are utilized jointly for the trigger information. In the second step we apply low order frequency response model [4] combined with the voltage dependent load models [7] to obtain the overall active power mismatch and hence the total amount of reactive power shed. In third step we use both voltage and frequency information for simultaneous active and reactive load shedding. In the active load shedding distribution process the frequency measurements are used together with the active power estimates provided by the tracing power flow. While for reactive power load shedding distribution it requires voltage information along with the reactive power estimates obtained from tracing power flow, by following this process the appropriate amount of active and reactive power to be shed as the selected buses can be determine simultaneously.

In this analysis the role of synchrophasor is implementing the suggested load shedding schemes and corresponding algorithm for obtaining the information in section II. The conventional adaptive load shedding is present in section III. The introduces load shedding method is newly proposed in section IV. Experimental results based on real time simulation and provide explanation all provide section $\mathrm{V}$ and conclusion is given in section VI.

\section{II.SYNCHORPHASOR FOR LOAD SHEDDING}

\section{A.PMUs, synchrophasor and WAMCS}

PMUs, instruments providing so-called synchronized phasor or synchrophasor measurement have been generally developed in power systems in the previous days, mainly in high voltage transmission networks. In the measure [13] of synchrophasor is defined as a composite numbers represents the either voltage or current, at the fundamental frequency, use a standard time reference. The synchrophasor representation $\mathrm{A}$ of a sinusoidal signal a $(\mathrm{t})=\sqrt{2} \mathrm{~A} \cos (2 \pi f t+\varphi)$ is the complex value is given by

$$
\mathrm{A}=\mathrm{A} \cdot e^{j \varphi}=\mathrm{A} \cdot(\cos \varphi+\sin \varphi)
$$

Where $\mathrm{A}$ is the root-mean-square (rms) value of the signal $\mathrm{a}(\mathrm{t})$, and $\varphi$ is its instantaneous phase angle that is referred to a common reference time (UTC, Universal Coordinated Time). Both voltage and frequency values can be measure by PMUs directly [11].WAMCS is a central platform that may use synchrophasor measurement is collected from a wide area for reason of centralized monitoring and control, like assessment and maintaining stability [9], [15].
The time-stamped synchrophasor data are determined by PMUs at high rate and with high accuracy [12]. Hence they are very effective for tracing the dynamic evaluation in the power system operation. Large disturbances are occur mostly bylines or generators tripping which connection/disconnection condition monitoring can be positioning by PMUs [8].

B. Role of Synchrophasor Measurement in the Proposed Load Shedding scheme

Synchrophasor measurement have been capable of new applications, such as combination of load shedding using both voltage and frequency information [15]. In the traditional supervisory control and data acquisition (SCADA) systems, usually only the non-synchronized magnitude measurements are received directly from the remote terminal unit (RTU), these are designed for lower rate and accuracy. The phase angles are taken directly from the PMU measurements, they monitoring in power system can be significantly improved [12] especially for centralized applications including power flow analysis and systematic voltage stability assessment. In the procedure the WAMCS and PMUs provide the environment for implementing UVLS and UFLS are in same Platform that is easy for realization of adaptive combinational load shedding

\section{TABLE I}

\section{PHASOR MEASURMENT FOR DIFFERENT ISSUES AND STEPS OF LOAD SHEDING}

\begin{tabular}{|l|l|l|}
\hline Role & $\begin{array}{l}\text { Measurements } \\
\text { needed from PMUs }\end{array}$ & $\begin{array}{l}\text { Involvement in } \\
\text { load shedding }\end{array}$ \\
\hline $\begin{array}{l}\text { Frequency stability } \\
\text { assessment }\end{array}$ & $\begin{array}{l}\text { The frequency and rate } \\
\text { of change of frequency } \\
\text { of each generator, and } \\
\text { the frequency } \\
\text { deviation of each load } \\
\text { bus }\end{array}$ & Step 1,2,3 \\
\hline $\begin{array}{l}\text { Voltage stability } \\
\text { assessment }\end{array}$ & $\begin{array}{l}\text { The voltage magnitude } \\
\text { and phase angle of } \\
\text { each bus }\end{array}$ & Step 1,3 \\
\hline Power flow tracing & $\begin{array}{l}\text { The voltage magnitude } \\
\text { and phase angle of } \\
\text { each bus }\end{array}$ & Step3 \\
\hline
\end{tabular}

In the proposed load shedding schemes, the phasor measurements are used in each step of load shedding procedure, as shown in Table 1.

C. Voltage Stability Assessment Based on Modal Analysis

Model analysis based on the Jacobian matrix in (2) is a proportion analysis method for global voltage stability assessment. 
$\left[\begin{array}{l}\Delta \mathrm{P} \\ \Delta Q\end{array}\right]=\left[\begin{array}{ll}J_{P \theta} & J_{P V} \\ J_{Q \theta} & J_{Q V}\end{array}\right]\left[\begin{array}{l}\Delta \theta \\ \Delta V\end{array}\right]$

It is consider in this paper that the Jacobian matrix is calculated from the measured magnitude and phase angle values of the voltage from PMUs.

It is prepared for extraction of the relationship between reactive power and voltage magnitude. $\Delta P=0$ is generally to obtain the following relationship.

$\Delta Q=\left[J_{Q V}-J_{Q \theta} J_{P \theta}^{-1} J_{P V}\right] \Delta V$

It can be also represented as

$\Delta V=J_{R}^{-1} \cdot \Delta Q$

For calculating $J_{R}^{-1}$ directly, a matrix method is generally applied according to (5)

$J_{R}^{-1}=E_{R} \xi^{-1} E_{L}$

So (4) can be modified as

$$
\begin{gathered}
\Delta V=E_{R} \xi^{-1} E_{l} \Delta Q \\
=\sum_{l} \frac{E_{R, l} E_{L, l}}{\lambda_{l}} \Delta Q
\end{gathered}
$$

Where

- $\quad E_{R}$ : right eigenvector matrix of $J_{R}$ :

- $E_{L}$ :left eigenvector matrix of $J_{R}$ :

- $\xi$ :diagonal eigenvalue matrix of $J_{R}$ :

- $E_{R, l}$ : lth column of $E_{R}$ :

- $E_{L, l}:$ lth row of $E_{R}$ :

- $\quad \lambda_{l}: 1^{\text {th }}$ eigenvalue of $J_{R}$ and the corresponding mode.

The corresponding $1^{\text {th }}$ modal voltage variation is

$$
\Delta V_{m l}=\frac{\Delta Q_{m l}}{\lambda_{l}}
$$

If $\lambda_{l} \leq 0$, the $1^{\text {th }}$ modal collapse. Corresponding to minimum eigenvalue $\lambda_{\min }$ stands for the mode that is the most prostrate to collapse, it can be used as voltage stability indicator for the total system.

V-Q sensitivity at bus $\mathrm{k}$ can be computed by

$$
V Q S_{k}=\frac{\partial V_{k}}{\partial Q_{k}}=\sum_{l} \frac{\mu_{k l} \cdot \eta_{l k}}{\lambda_{l}}
$$

Where $\mu_{k l}$ is the $k_{t h}$ element of $E_{R, l} \cdot \eta_{l k}$ Is the $k_{t h}$ element of $E_{L, l}$.
A positive value of $V Q S_{k}$ indicates that the relationship between the change of voltage and the reactive power is stable at bus $\mathrm{k}$, and the voltage is more sensitive to reactive power variation as $V Q S_{k}$ it presents an unstable operating condition [17].

The elements for voltage stability assessment based on model analysis are used in this paper as follows:

1) $\lambda_{\min }$ is applied in the load shedding trigger determination from a global view: also the assessment index for different methods comparison in the regain steady state after load shedding:

2) $V Q S_{k}$ Is applying in the reactive power load shedding distribution.

\section{Power Flow Tracing Method for Load Shedding:}

Power flow tracing is a method to determine the proportional usage of lines and generators by the power consumers, and the results will act as the reference for charging in the electricity market. As the development of technology, now the power flow tracing have commonly applied in the study of the power system analysis, such as load shedding. That is based on the power flow results which can be determined by using the voltage magnitude and phase angle measurement provided directly from the PMUs.

The so-called proportional sharing principle, as denoted as in [16] and [17], is the center of power flow tracing method to establish for the power allocations. They generally power flow algorithm can be classified as Upstream-looking algorithm and Downstream-looking algorithm [16], both are taken as same loads.

The only difference is they opposes to the line losses to the loads or generators. In this paper we can consider the downstream-looking algorithm because to trace the power of each load bus received from each line and generators.

According to the principle that the inflow equals the outflow at any bus $g$ can be defined as

$$
\mathrm{P}_{\mathrm{g}}=\sum_{h \in D_{g}}\left|P_{h g}\right|+\sum_{h \in D_{g}} \mid \text { Ploss }_{g h} \mid+\mathrm{P}_{\mathrm{Lg}}
$$

Where $D_{g}$ is the set of busses supplied directly by bus $\mathrm{g}, \mathrm{P}_{\mathrm{hg}}$ is the active power flow bus $\mathrm{h}$ to $\mathrm{g}, \mathrm{P}_{\mathrm{lg}}$ is the total active power load at bus $\mathrm{g}$, and Ploss $\mathrm{gh}_{\mathrm{g}}$ is the active power loss of line connecting bus $g$ and bus $h$.

A downstream distribution matrix $A_{d}$ is defined with corresponding entries $\left[\mathrm{A}_{\mathrm{d}}\right]_{\mathrm{gh}}$ according to 


$$
\left[\mathrm{A}_{\mathrm{d}}\right]_{\mathrm{gh}}=\left\{\begin{array}{c}
1, \quad \text { if } h=g ; \\
\frac{-\left|P_{h g}\right|}{P_{h}}, \text { if } h \in D_{g} ; \\
0, \text { otherwise. }
\end{array}\right.
$$

The active power contribution made by the generator $\mathrm{g}^{\text {th }}$ bus to active power load of the $\mathrm{k}^{\text {th }}$ bus is denoted as $\mathrm{P}_{\mathrm{Gg}, \mathrm{LK}}$ which can be determined as

$$
\mathrm{P}_{\mathrm{Gg}, \mathrm{Lk}}=\frac{P_{G g} \cdot P_{L k}}{P_{g}} \cdot e_{g}^{T} A_{d}^{-1} e_{k}
$$

Where $e_{\mathrm{g}}$ and $\mathrm{e}_{\mathrm{k}}$ represents the unit column vector where the $\mathrm{g}^{\text {th }}$ or $\mathrm{k}^{\text {th }}$ element equals one and the others are zero; $\mathrm{P}_{\mathrm{Gg}}$ is the active power supplied by the generator at the $\mathrm{g}^{\text {th }}$ bus, while $\mathrm{P}_{\mathrm{LK}}$ is the total active power consumed at the $\mathrm{k}^{\text {th }}$ bus.

Correspondingly, the contribution from the active power flow $\mathrm{P}_{\mathrm{gh}}$ of line $(\mathrm{g}, \mathrm{h})$ to the active power load of the $\mathrm{k}^{\text {th }}$ bus is calculated as

$$
\mathrm{P}_{\mathrm{Bg}, \mathrm{Lk}}=\frac{P_{G g} \cdot P_{L k}}{P_{g}} \cdot e_{g}^{T} A_{d}^{-1} e_{k}
$$

Where $\mathrm{p}_{\mathrm{gh}}$ is the active power flow from bus $\mathrm{g}$ to bus $h$. In the manner the reactive power flow tracing also be defined. The obtained tracing active and reactive power from the generators and lines to load buses provides the process for deciding the load shedding distribution in terms of power.

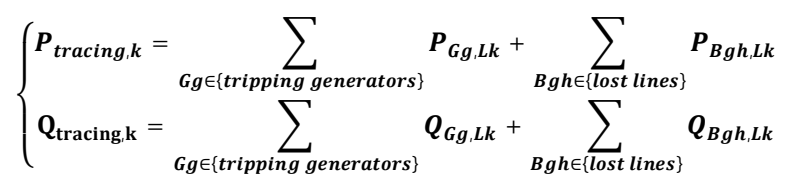

Where $p_{\text {tracing,k. }} Q_{\text {tracing,k }}$ : calculated by power flow tracing approach, total active and reactive power at the $\mathrm{k}^{\text {th }}$ load bus receives tripping generators and lines are calculated before disturbances.

\section{DESCRIPTION OF THE EXISTING LOAD SHEDDING PROCESS}

\section{A. Trigger For Load Shedding}

The trigger is a signal that starts the load shedding action. The first step of the load shedding process of the trigger is always based on the frequency or voltage information independently [5], [8]. The local method to considering both voltage and frequency jointly at each bus has been proposed because a local method to activate the trigger. When the trigger used can be explained in details in the section IV. A.

\section{B. power Imbalance Estimation}

The important thing of the adaptive load shedding method, the total power imbalance can be calculated adaptively according to different disturbances [5]. The calculation method is based on the low-order system frequency response (SFR) model. This can be calculated for the active power deficit of the $\mathrm{i}^{\text {th }}$ generators as shown in(14). The initial rate of change of frequency can be taken as in (14) can be obtained from PMUs. The active power imbalance $\Delta P_{\mathrm{Gi}}$ of the $i^{\text {th }}$ generator can be calculated as soon as the disturbance occurs by

$\Delta P_{G i}=\left[P_{m i}-P_{e i}\right]=\frac{2 H_{i} . S_{i}}{f_{n}} \frac{d f_{G i}}{d t}$

Where

$\mathrm{H}_{\mathrm{i}}$ : inertia constant of the $\mathrm{i}^{\text {th }}$ generator:

$\mathrm{S}_{\mathrm{i}}$ : rated apparent power (MVA) of the $\mathrm{i}^{\text {th }}$ generator

$f_{n}$ : rated system frequency $(50 \mathrm{~Hz}$ in this paper)

$f_{G i}$ : Frequency of the $\mathrm{i}^{\text {th }}$ generator

$P_{m i}:$ Mechanical power of the $\mathrm{i}^{\text {th }}$ generator

$P_{e i}:$ Electrical power of the $\mathrm{i}^{\text {th }}$ generator

Combined the individual calculation of active power deficits of the generators in the power system, we can calculate the total active power imbalance $\Delta P$

$$
\Delta P=\sum_{i=1}^{N} \Delta P_{G i}
$$

Where $\mathrm{N}$ is the total number of generators.

From (14) and (15). Together with frequency for equivalent inertial center

$f_{c}=\sum_{i=1}^{N} H_{i} \cdot S_{i} \cdot \frac{d f_{G i}}{d t} / \sum_{i=1}^{N} H_{i} \cdot S_{i}$, as defined as (15),a new equation is

$$
\Delta P=\frac{2 \sum_{i=1}^{N} H_{i} \cdot S_{i}}{f_{n}} \frac{d f_{C}}{d t}=\xi \frac{d f_{C}}{d t}
$$

Where

- $\frac{d f_{c}}{d t}=\sum_{i=1}^{N} H_{i} \cdot S_{i} \cdot \frac{d f_{G i}}{d t} / \sum_{i=1}^{N} H_{i} . S_{i}$, the rate of change of frequency for the equivalent inertial center

- $\quad \xi=\frac{2}{f_{n}} \sum_{i=1}^{N} H_{i} . S_{i}$, a constant value. 


\section{Existing Method for Load Shedding Distribution}

Now in this step we can calculate the exact shedding amount of each load bus. The conventional load shedding distribution can takes the information of $\mathrm{df}_{\mathrm{c}} / \mathrm{dt}$ or frequency change the $\Delta f[6]$ at each bus, connectively to the initial load condition. We can take the large disturbance may cause the value of $\mathrm{df} / \mathrm{dt}$ of load busses to be un reliable in the process of load shedding distribution $\Delta f$ is usually chosen as the respective frequency information used in the load shedding distribution.

The amount of reactive power load to be shed at the $\mathrm{j}^{\text {th }}$ load bus, denoted as $\Delta P_{\mathrm{Lj}}$ is given according [6] by

$\Delta P_{L j}=\frac{\Delta f_{L j .} P_{L o, j}}{\sum_{j=1}^{M}\left(\Delta f_{L j .} P_{L o, j}\right)} \cdot \Delta P$

Where $\Delta \mathrm{f}_{\mathrm{Lj}}$ : frequency deviation at the $\mathrm{j}^{\text {th }}$ load bus compared to the rated frequency $(50 \mathrm{~Hz})$ in this paper

$P_{L o, j}$ : amount of active power load at the $j^{\text {th }}$ bus before disturbances

M: total number of load buses.

In this method of load shedding distribution, load bus with high initial load and a large frequency deviation ends up with a larger share of load curtailment. In the small and large disturbances they apply the local voltage stability index called VSRI and voltage deviations. When large disturbances occurs the voltage deviation is consider.

$$
\Delta P \Delta_{L j}=\frac{\Delta V_{L j}}{\sum_{j=1}^{M}\left(\Delta V_{L j}\right)} . \Delta P
$$

$\Delta \mathrm{V}_{\mathrm{Lj}}$ : voltage deviation at the $\mathrm{j}^{\text {th }}$ load bus compared to the voltage before the disturbance.

Voltage deviation [8] and index VQS as defined as $\Delta P_{L j}=\frac{\frac{\Delta V_{L j}}{V Q S_{j}}}{\sum_{j=1}^{M}\left(\frac{\Delta V_{L j}}{V Q S_{j}}\right)} \cdot \Delta P$

The reactive is not involved in the calculation of (19). The information used in (19) is not based in synchrophasor measurement.

\section{IV.PROPOSED METHOD FOR LOAD SHEDDING}

In three main steps the proposed adaptive combinational load shedding method, that both voltage and frequency information are used.

\section{A. Triggering for load Shedding}

In this work global triggers are used in proposed method, so therefore we consider $\boldsymbol{\lambda}_{\min }, \mathrm{f}_{\mathrm{c}}$ and $\mathrm{df}_{\mathrm{c}} / \mathrm{dt}$ as triggers simultaneously with corresponding thresholds:

- $\boldsymbol{\lambda}_{\min }$ : the minimum eigenvalue of the Jacobian matrix smaller than zero;

- $\mathrm{f}_{\mathrm{c}}$ : out of the normal frequency range [49.5, 50.5]

- $\mathrm{dfc/dt:}$ the rate of the normal frequency in the abnormal range of $[-1.5,-0.2] \mathrm{hz} / \mathrm{s}$.

Therefore, depending on the fault type, any of the types may supers the individual threshold thus initiating the load shedding process.

\section{B. Improved Power Imbalance Estimation}

In the classic SFR model, only inertia constant of generators and frequency information are considered. However, as suggested in IEEE standard for UFLS the load model with voltage and frequency dependence should also be included in the design for UFLS in order to achieve exact active power imbalance estimation. The change of frequency [7] is always smaller than the voltage variation, only the voltage dependence of load model as in (20) is applied in the load shedding scheme in this paper

$$
\begin{aligned}
& P_{L, j}=P_{L 0, j} \times\left(\frac{V_{j}}{V_{0, j}}\right)^{\alpha j}, Q_{L, j}=Q_{L, j} \times\left(\frac{V_{j}}{V_{0, j}}\right)^{\beta j} \\
& P_{L}=\sum_{j-1}^{M} P_{L, j}, Q_{L}=\sum_{j-1}^{M} Q_{L, j}
\end{aligned}
$$

Where

- $\mathrm{P}_{\mathrm{L}}, \mathrm{Q}_{\mathrm{L}}$ : the current total active and reactive power load of all the load buses:

- $P_{L, j}, Q_{L, j}$ : the current active and reactive power load of the jth load bus before the disturbance:

- $\mathrm{P}_{\mathrm{LO}, \mathrm{j}}, \mathrm{Q}_{\mathrm{LO}, \mathrm{j}}$ : the initial active and reactive power load of the jth load bus after disturbance:

- $\mathrm{V}_{\mathrm{j}}$ : the current voltage magnitude of the jth load bus after the disturbance:

- $\mathrm{V}_{0, \mathrm{j} \text { : }}$ the initial voltage magnitude of the jth load bus before the disturbance:

- $\alpha_{j}, \beta_{j}$ : factor depicting the active and reactive power dependence of the load on voltage deviations .which are set to 1 and 2,respectively , as introduced in [7]:

- M: total number of load buses. 
Based on this load model, the method proposed [7] in is adopted in this paper to improve active power imbalances estimation the total active power imbalances of the generators considering the voltage dependent load modeling,

$$
\Delta \mathrm{P}_{\text {improvement }} \text { is defined as }
$$

$\Delta P_{\text {improvement }}=\Delta P+\sum_{j=1}^{M} P_{L 0, j} \times\left[\left(\frac{V_{j}}{V_{o, j}}\right)^{\alpha j}-1\right]$

Where $\Delta P$ is the total active power imbalance of the generators based on the classic SFR model. $\Delta P$ In (17), (18) and (19) are replaced with $\Delta P_{\text {improvement }}$ for the test in this paper.

Once $\Delta P_{\text {improvement }}$ is estimated by (22), we propose to determine $\Delta Q_{\text {improvement }}$ as follows:

$$
\Delta Q_{\text {improvement }}=\frac{Q_{L 0}}{P_{L 0}} \cdot \Delta P_{\text {improvement }}
$$

$\mathrm{P}_{\mathrm{Lo}}$ : total active power load before load shedding

$\mathrm{Q}_{\mathrm{Lo}}$ : total reactive power before load shedding

\section{New Method for Load Shedding Distribution}

In this section we can improve the load shedding distribution method and also establish the main team of this paper.

The existing method as represented in (17), (18) and (19) could be correct solutions for the distribution of load shedding. They are two major points is given below.

1) Reactive power is not taken in the load shedding distribution: this may leads to deficient load shedding distribution, thus reducing the effect of load shedding

2) Voltage stability issue is not taken jointly with reactive power: the separation of voltage and reactive power it gives to the fallacious information.

The load shedding distribution factor for active power (LSDFP) and load shedding distribution factor for reactive power (LSDFQ) for load buses. These LSDFP and LSDFQ can be measured in (24) and (25) represents the proportional to the active and reactive power imbalance .LSDFP includes only frequency and active power and LSDFQ includes the voltage and reactive power.

$$
\left\{\begin{aligned}
\operatorname{LSDFP}_{\mathrm{j}} & =\frac{\Delta \mathrm{f}_{\mathrm{L}, \mathrm{j}} \cdot \mathrm{P}_{\text {tracing, }}}{\sum_{\mathrm{j}=1}^{\mathrm{M}}\left(\Delta \mathrm{f}_{\mathrm{l}, \mathrm{j}} \cdot P_{\text {tracing, }}\right)} \\
\mathrm{LSDFQ}_{\mathrm{j}} & =\frac{\mathrm{VQS}_{\mathrm{j}} \cdot \mathrm{Q}_{\text {tracking,j }}}{\sum_{\mathrm{j}=1}^{\mathrm{M}}\left(\mathrm{VQS}_{\mathrm{j}} \cdot \mathrm{Q}_{\text {tracing, }}\right)}
\end{aligned}\right.
$$

$$
\left\{\begin{aligned}
\Delta \mathrm{P}_{\mathrm{Lj}} & =\Delta \mathrm{P}_{\text {improvement }} \cdot \mathrm{LSDFP}_{\mathrm{J}} \\
\Delta \mathrm{Q}_{\mathrm{Lj}} & =\Delta \mathrm{Q}_{\text {improvement }} \cdot \mathrm{LSDFQ}_{\mathrm{j}}
\end{aligned}\right.
$$

Where

- $\Delta \mathrm{f}_{\mathrm{L}, \mathrm{j}}$ : frequency deviation to the rated frequency $\left(50 \mathrm{~Hz}\right.$ in this paper)of the $\mathrm{j}^{\text {th }}$ load bus;

- VQS: sensitivity of voltage variation to reactive power of the $\mathrm{j}^{\text {th }}$ load bus;

$\Delta \mathrm{f}_{\mathrm{L}, \mathrm{j}}$ and $\Delta \mathrm{Q}_{\mathrm{L}, \mathrm{j}}$ are to be taken in (24), (25), from the theory point of view active and reactive power load shedding at each can be taken separately. Generally the load shedding can be operated to $\Delta \mathrm{p}_{\mathrm{Li}}$ it leads to the controllability of reactive power curtailment $\Delta Q_{L j}^{\prime}$.it means that the controllability of reactive power is not considered. This leads to both active and reactive power curtailment, and the ratio is decided by the power factor of their initial load before disturbance as shown in (26)

$$
\frac{\Delta Q_{L j}^{\prime}}{\Delta P_{L j}}=\frac{Q_{L 0, j}}{P_{L 0, j}}
$$

Therefore, there is a mismatch between $\Delta \mathrm{Q}_{\mathrm{L}, \mathrm{j}}$, as determined by reactive power load shedding and $\Delta Q_{L j}^{\prime}$ caused by the curtailment action only according to the active power. this difference, through, can be compensated by the reactive power compensating devices such as the static compensator(STATCOM), static VAR compensator(SVC), switching capacitor banks and so on. It can also regard as a kind of coordinated reactive power compensation from the point of view of the overall system during the load shedding.

D. New Indices for evaluating the effect of load shedding on loadability

Due to the load model in (20) and the improved power imbalance estimation in (22) applied in this paper, three new indices are selected as metric for evaluating the effect of load shedding. The indices are defined as follows:

- $\mathrm{P}_{\text {Loss,after }}$ : the total active power loss of the whole network in the recovered steady state after load shedding;

- $\mathrm{P}_{\mathrm{L}, \mathrm{after}}$ : the total active power load in the recovered steady state after load shedding;

- $\mathrm{Q}_{\mathrm{L}, \mathrm{after}}$ : the total reactive power load in the recovered steady state after load shedding;

The load modeling in the form of voltage dependence is applied in this paper, $\mathrm{P}_{\mathrm{l}, \text { after }}$ in (27) and $\mathrm{Q}_{\mathrm{L}, \text { after }}$ in 
(28)are calculated. $\mathrm{P}_{\mathrm{l}, \text { after }}$ and $\mathrm{Q}_{\mathrm{L}, \text { after }}$ are closely dependent because to allocate the load shedding.

$$
\begin{aligned}
& \boldsymbol{P}_{\boldsymbol{L}, \boldsymbol{a f t e r}}=\sum_{j=1}^{M}\left[\begin{array}{c}
\left.\left(\boldsymbol{P}_{L 0, j}-\Delta \boldsymbol{P}_{L \boldsymbol{j}}\right) \times\left(\frac{V_{j, a f t e r}}{V_{0, j, a f t e r}}\right)^{\alpha, j}\right] \\
\neq \boldsymbol{P}_{L \mathbf{0}}-\Delta \boldsymbol{P}_{\text {improvement }}
\end{array}\right. \\
& \mathrm{Q}_{\mathrm{L}, \text { after }}=\sum_{\mathrm{j}=1}^{\mathrm{M}}\left[\left(\mathrm{Q}_{\mathrm{L} 0, \mathrm{j}}-\Delta \mathrm{Q}_{\mathrm{Lj}}\right) \times\left(\frac{\mathrm{V}_{\mathrm{j}, \mathrm{after}}}{\mathrm{V}_{0, \mathrm{j}, \mathrm{after}}}\right)^{\beta j}\right] \\
& \neq \mathrm{Q}_{\mathrm{L} 0}-\Delta \mathrm{Q}_{\text {improvement }}
\end{aligned}
$$

Where :

$\mathrm{V}_{\mathrm{o}, \mathrm{j}, \text { after }}$ : the initial voltage magnitude of the $\mathrm{j}^{\text {th }}$ load bus after load shedding;

$\mathrm{V}_{\mathrm{j}, \text { after }}$ : voltage magnitude of the $\mathrm{j}^{\text {th }}$ load bus in the steady state after load shedding

\section{TESTING RESULTS AND DISCUSSION}

\section{A. Classification of Load Shedding Methods}

The distribution of load shedding, the load shedding can be classified four methods and denoted as M1, M2, M3 and M4 in Table II. In this the first and second have the same load shedding process.

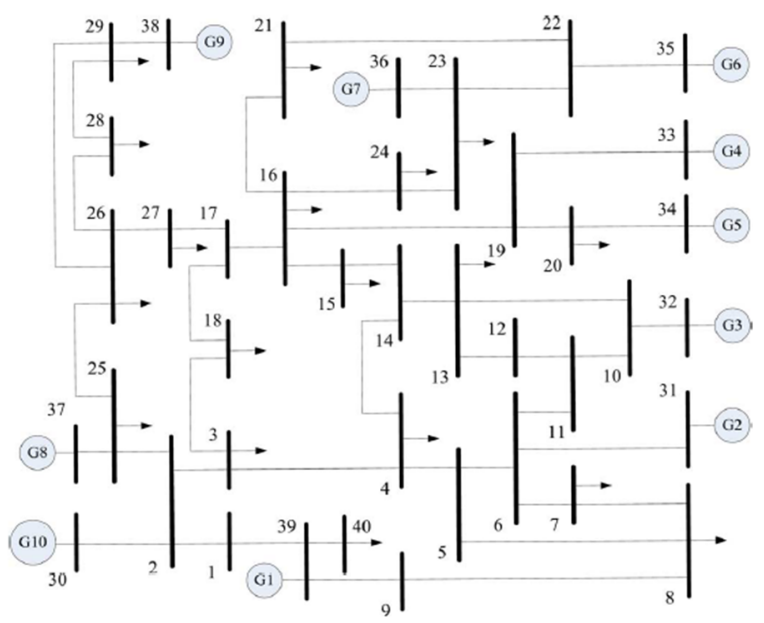

Fig. 1. Topology of modified IEEE 39-bus system

TABLE II

\section{CLASSIFICATION OF METHODS FOR LOAD SHEDDING}

\begin{tabular}{|l|l|l|}
\hline \multirow{2}{*}{ Method No } & \multicolumn{2}{|l|}{ Factors in load shedding distribution } \\
\cline { 2 - 3 } & LSDFP & LSDFQ \\
\hline M1 & $\begin{array}{l}\Delta f_{\mathrm{Li}} \text { and initial active } \\
\text { power } \mathrm{P}_{\mathrm{Lo}, \mathrm{i}}\end{array}$ & Equal to LSDFP \\
\hline $\mathrm{M} 2$ & $\Delta \mathrm{V}_{\mathrm{Li}}$ & Equal to LSDFP \\
\hline $\mathrm{M} 3$ & $\Delta \mathrm{V}_{\mathrm{Li}}$ and $1 / \mathrm{VQS}_{\mathrm{i}}$ & Equal to LSDFP \\
\hline $\mathrm{M} 4$ & $\mathrm{P}_{\text {tracing, } \mathrm{I}}$ and $\Delta \mathrm{f}_{\mathrm{Li}}$ & $\mathrm{Q}_{\text {tracing, } \mathrm{I}}$ and $\mathrm{VQS}$ \\
\hline
\end{tabular}

\section{B. LSDFP and LSDFQ in Load Shedding Methods.}

Fig. 2 shows that LSDFP of M1, M2 and M3 gives the different effects in the same bus. M4 gives the LSDFP and LSDFQ of each bus are different, which gives to the active and reactive powers at different properties. M4 concentrates the few load buses in vicinity of tripping generators and transmission line for bus 4, 7, 8 and 12 different lines in the fact that power tracing is applied in M4, and this is the main advantage of load shedding distribution. We can divide total power uniformly to each load bus this gives the initial load before disturbance.

\section{Comparison of Transient Behavior of different load shedding methods}

The disturbance is applied in this method and it is obtain $\Delta \mathrm{P}_{\text {improvement }}$ as defined in (22). From the results the escapes collapse, and stay at different new steady state depending on the chosen method on the load shedding distribution. The load shedding with different methods are shown in fig 2-5.

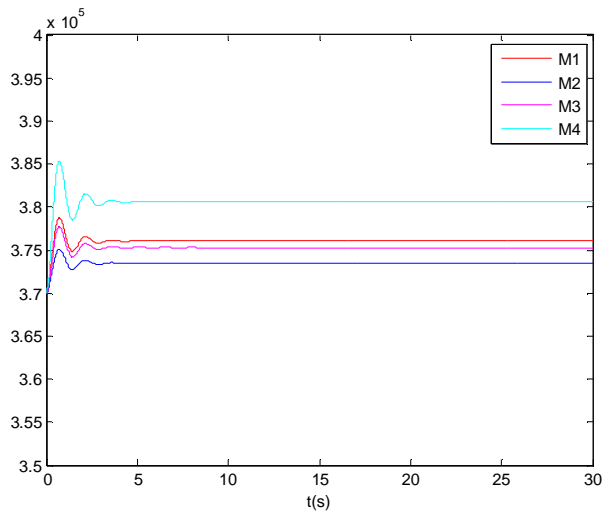

Fig.2. Mean voltage of all the buses in the load shedding

Fig.2gives similar behavior of the all methods and presenting fast and large disturbances occurs and new value after a short oscillation thanks to load shedding actions

Fig.3-5 represents the comparison of $\boldsymbol{\lambda}_{\min } . \mathrm{f}_{\mathrm{c}}$ and $\mathrm{df}_{\mathrm{c}} / \mathrm{dt}$ for all four methods: during the process from study state before disturbance from the system recovery. Fig6 $\boldsymbol{\lambda}_{\min }$ of M4 is always higher than the other in positive ranges, mean that M4 keeps the system voltage more stable all the time. Fig 5 shows that the amplitude of the oscillation of M4 is the smallest. 


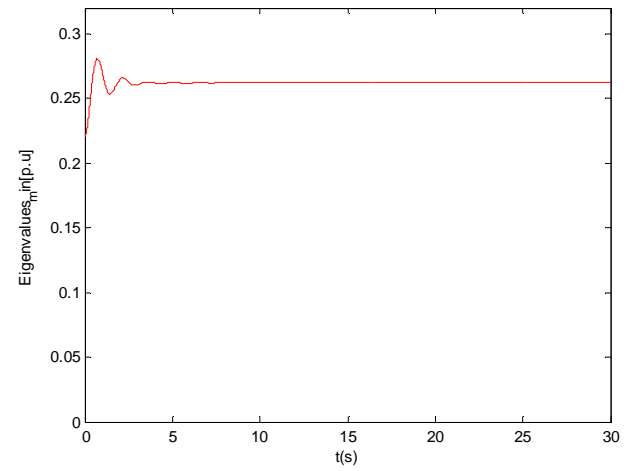

Fig.3. minimum eigen value of each method in the load shedding process

The maximum deviation of $f_{c}$ and maximum deviation of mean voltage $\mathrm{V}_{\text {mean }}$ of all load busses during the transient process, the time for $\mathrm{f}_{\mathrm{c}}$ and $\mathrm{V}_{\text {mean }}$ to re-settle to a new study state value. The oscillation during $\mathrm{t}_{\mathrm{osc}}$ is defined as

$$
t_{\text {osc }}=t_{n e w \_s t u d y}-t_{f}
$$

Where $t_{f}$ is the time when the fault occurs, while the

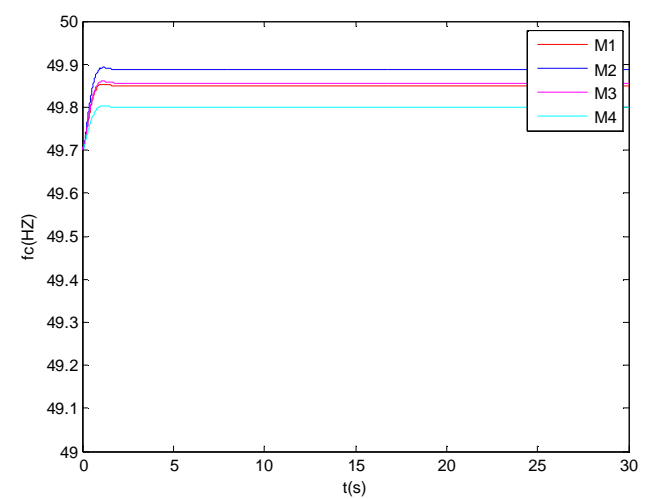

Fig.4. $\mathrm{f}_{\mathrm{c}}$ of each method of load shedding process

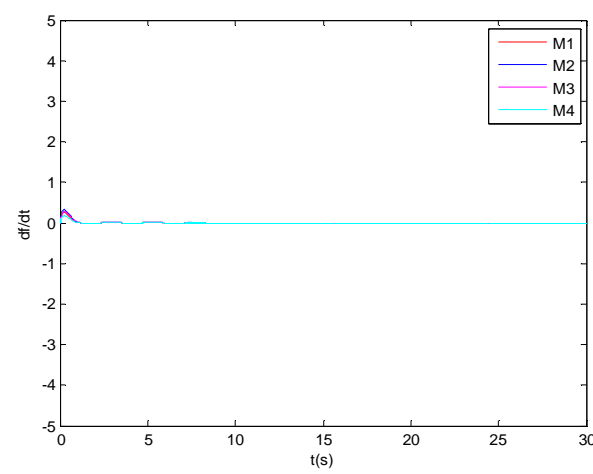

Fg.5. $\mathrm{df}_{\mathrm{c}} / \mathrm{dt}$ of each method in the load shedding process

\section{TABLE III}

Comparison Among Load Shedding Methods During The Transcient Process

\begin{tabular}{|c|c|c|c|c|}
\hline \multirow[b]{2}{*}{$\begin{array}{l}\text { Condi } \\
\text {-tions }\end{array}$} & \multicolumn{4}{|c|}{ Evaluation indices } \\
\hline & $\begin{array}{l}\text { Maximum } \\
\text { deviation of } \\
\mathrm{f}_{\mathrm{c}}(\mathrm{Hz})\end{array}$ & $\begin{array}{l}\text { Maximum } \\
\text { deviation of } \\
\mathrm{V}_{\text {mean }}(\mathrm{kV})\end{array}$ & $\begin{array}{l}\text { Oscillati } \\
\text { on } \\
\text { duration } \\
\text { of } \mathrm{f}_{\mathrm{c}}(\mathrm{s})\end{array}$ & $\begin{array}{l}\text { Oscillation } \\
\text { duration } \\
\text { of } \quad V_{\text {mean }} \\
\text { (S) }\end{array}$ \\
\hline M1 & 0.1520 & 11.54 & 13.80 & 8.72 \\
\hline M2 & 0.1401 & 23.25 & 14.20 & 10.05 \\
\hline M3 & 0.1482 & 14.60 & 13.30 & 8.61 \\
\hline M4 & 0.1301 & 16.50 & 15.20 & 8.65 \\
\hline
\end{tabular}

$\mathrm{t}_{\text {new_steady }}$ is the time when system reaches a new study after load shedding. It can be determined by the change of $\mathrm{z}(\mathrm{t})$, as defined in the following

$$
t_{n e w \_s t e a d y}=\min \left\{\begin{array}{c}
t: \backslash Z(t+n . \Delta t)-Z(t) \mid \leq \mu ; \\
n=1,2, \ldots \ldots .10\}
\end{array}\right.
$$

Where $\Delta t$ is set as 0.04 seconds corresponding to rate of PMUs.the value of $\mu$ depends on the analysis objective, that $10^{-5} \mathrm{~Hz}$ is chosen for $\mathrm{f}_{\mathrm{c}}$ while $10^{-2} \mathrm{kV}$ is used in $\mathrm{V}_{\text {mean }}$ is used in this paper

The maximum deviation of $\mathrm{f}_{\mathrm{c}}$ and $\mathrm{V}_{\text {mean }}$ are defined as

$$
\Delta_{Z \max }=\max \left\{\backslash Z(t)-Z_{\text {new_steady }}(t) \mid\right\}
$$

Where $z_{\text {new_steady }}(t)$ is the value of $z(t)$ at the time point $t_{\text {new_steady }}$

The test results are explained in table $\mathrm{V}$. The best loadability of M4 as shown in the next sub-section. The voltage stability is considered the reactive power and voltage as a pair in the process of load shedding distribution.

\section{Comparison of Recovered Steady State in Aspects of Voltage and Frequency}

The steady states before disturbances and after load shedding with fore methods, five aspects are considered. The frequency for the equivalent inertial

\section{TABLE IV}

Comparison Among Load Shedding Methods In Frequency And Voltage

\begin{tabular}{|l|l|l|l|l|l|}
\hline \multirow{2}{*}{$\begin{array}{l}\text { Condi- } \\
\text { tions }\end{array}$} & \begin{tabular}{l}
$|l|$ \\
\cline { 2 - 6 } \\
$(\mathrm{Hz})$
\end{tabular} & $\begin{array}{l}\mathrm{\lambda}_{\min } \\
(\mathrm{P} . \mathrm{u})\end{array}$ & $\begin{array}{l}\mathrm{V}_{\max } \\
(\mathrm{kV})\end{array}$ & $\begin{array}{l}\mathrm{V}_{\text {mean }} \\
(\mathrm{kV})\end{array}$ & $\begin{array}{l}\mathrm{V}_{\min } \\
(\mathrm{kV})\end{array}$ \\
\hline $\begin{array}{l}\text { Before } \\
\text { disturb } \\
\text { ances }\end{array}$ & 49.71 & 0.2482 & 383.66 & 371.18 & 356.10 \\
\hline M1 & 49.85 & 0.2452 & 386.40 & 376.00 & 353.20 \\
\hline M2 & 49.89 & 0.2340 & 385.80 & 373.50 & 356.60 \\
\hline M3 & 49.86 & 0.2424 & 386.90 & 375.30 & 361.20 \\
\hline M4 & 49.80 & 0.2620 & 385.50 & 380.60 & 356.20 \\
\hline
\end{tabular}

ISSN: 2231-5381

http://www.ijettjournal.org 
TABLE V

Comparison Among Load Shedding Methods In Power

\begin{tabular}{|l|l|l|l|}
\hline \multirow{2}{*}{$\begin{array}{l}\text { Condi- } \\
\text { tions }\end{array}$} & \multicolumn{3}{|l|}{ Evaluation indices } \\
\cline { 2 - 4 } & $\begin{array}{l}\mathrm{P}_{\text {loss,after }} \\
(\mathrm{mW})\end{array}$ & $\begin{array}{l}\mathrm{P}_{\mathrm{L}, \text { after }} \\
(\mathrm{mW})\end{array}$ & $\begin{array}{l}\mathrm{Q}_{\mathrm{L}, \text { after }} \\
(\mathrm{mVAr})\end{array}$ \\
\hline M1 & 45.80 & 5798 & 1156 \\
\hline M2 & 52.68 & 58.6 & 1125 \\
\hline M3 & 55.49 & 5841 & 1275 \\
\hline M4 & 39.08 & 5895 & 1311 \\
\hline
\end{tabular}

Center $f_{c}$ of the system and indices of voltage of all the load buses are compared as shown in Table IV. The best voltage profile in M4 is kept in the new steady state, regardless of the mean and minimum voltage of all the load buses.

\section{E. Comparison of Recovered Steady State in Aspects of loadability}

From Table V, M4 achieves the least total active power loss of network in the new steady state. The effect of M4 is the active and reactive loading is kept at a higher level than the others. The reason can be understood from two aspects:

- All the four methods compared the total amount of load shedding is identical owing to the same distributions and the same method for total active power imbalance.

- The better voltage profile are achieved by taking into considering the index VQS together reactive power in load shedding.

The proposed method M4 exhibits the best performance in relation to steady state after load shedding from the point of each proposed index.

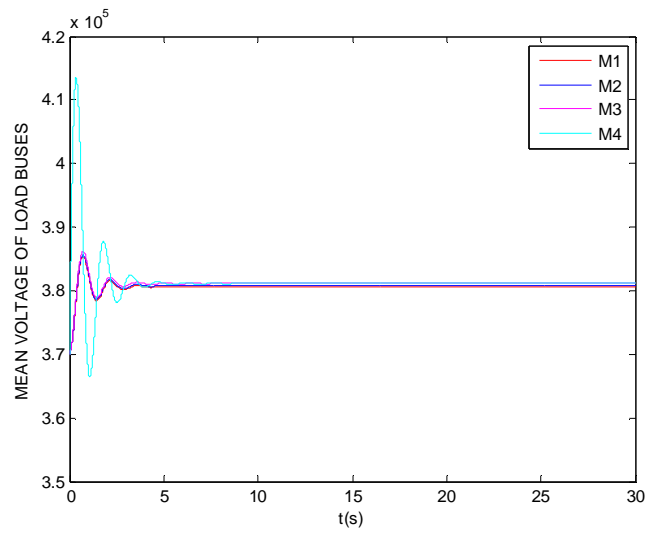

Fig.6. $\mathrm{V}_{\text {mean }}$ of method M4 with different time delays in the load shedding process.

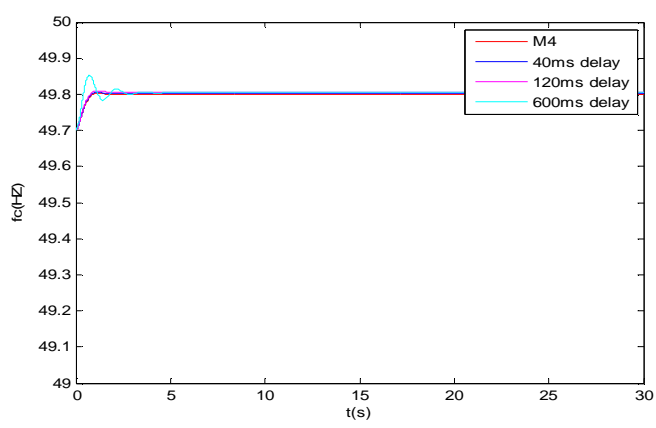

Fig 7. $\mathrm{f}_{\mathrm{c}}$ of method M4 with different time delays in the load shedding process.

\section{F. Impact of Time Delay Caused by Communications on Load Shedding Results}

The time delay in synchrophasor transmission is the biggest challenge for load shedding. As shown in fir.9 and 10, as time delay increases, the maximum deviation of $f_{c}$ and $V_{\text {min }}$ during the oscillations becomes larger. The limit of impact for the time delay is between 2 seconds and 4 seconds, behind which the load shedding process may fail.

\section{G. Test Results in condition of Simultaneous Tripping of Two Generators}

In this scenario the disturbance caused by tripping of generator 5 and generator 6 simultaneously is assumed. The capacities of some generators are adjusted to allow from the system collapse in this fault condition when after disturbances occurs all the

TABLE VI

Comparison Among Load Shedding Methods In Frequency And Voltage- In Condition Of Two Generators Tripping

\begin{tabular}{|l|l|l|l|l|l|}
\hline \multirow{2}{*}{ Condi-tions } & \multicolumn{5}{|l|}{ Evaluation indices } \\
\cline { 2 - 6 } & $\begin{array}{l}\mathrm{f}_{\mathrm{c}} \\
(\mathrm{Hz})\end{array}$ & $\begin{array}{l}\lambda_{\min } \\
(\mathrm{P} . \mathrm{u})\end{array}$ & $\begin{array}{l}\mathrm{V}_{\max } \\
(\mathrm{kV})\end{array}$ & $\begin{array}{l}\mathrm{V}_{\text {mean }} \\
(\mathrm{kV})\end{array}$ & $\begin{array}{l}\mathrm{V}_{\min } \\
(\mathrm{kV})\end{array}$ \\
\hline $\begin{array}{l}\text { Before } \\
\text { disturbance }\end{array}$ & 49.81 & 0.2563 & 395.69 & 373.96 & 365.47 \\
\hline M1 & 50.00 & 0.3200 & 390.01 & 384.40 & 371.10 \\
\hline M2 & 49.86 & 0.3100 & 394.60 & 382.50 & 363.40 \\
\hline M3 & 49.81 & 0.2730 & 383.20 & 372.60 & 356.80 \\
\hline M4 & 49.92 & 0.3120 & 390.15 & 384.20 & 376.40 \\
\hline
\end{tabular}

TABLE VII

Comparison Among Load Shedding Methods In Power-In Condition Of Two Generators Tripping

\begin{tabular}{|l|l|l|l|}
\hline \multirow{3}{*}{ Conditions } & \multicolumn{3}{|c|}{} \\
\cline { 2 - 4 } & $\begin{array}{l}\text { Evaluation indices } \\
\mathrm{P}_{\text {loss,after }} \\
(\mathrm{mW})\end{array}$ & $\begin{array}{l}\mathrm{P}_{\mathrm{L}, \text { after }} \\
(\mathrm{mW})\end{array}$ & $\begin{array}{l}\mathrm{Q}_{\mathrm{L}, \text { after }} \\
(\mathrm{mVAr})\end{array}$ \\
\hline M1 & 30.80 & 4891 & 1072 \\
\hline M2 & 41.60 & 5029 & 1082 \\
\hline M3 & 48.15 & 5027 & 1121 \\
\hline M4 & 30.15 & 5072 & 1311 \\
\hline
\end{tabular}


Load shedding methods can maintain the stability system and bring the system into a new steady state. In addition, conclusions can be obtained from tableVI and $\mathrm{V}$ that the M4 is still the most effective method at strengthening the new steady state after executing the same total amount of active power curtailment.

\section{CONCLUSIONS}

To overcome the disadvantages of the existing adaptive combinational load shedding methods, a load shedding scheme based on a new load shedding distribution method using combined frequency and voltage stability assessment proposed in this paper.

The proposed load shedding process we can use the synchrophasor measurements. In this paper reactive power is used directly into the reactive power load shedding distribution together with active power load shedding distribution, to address the voltage stability issue directly and more effectively in the load shedding process. The model analysis is to address the voltage stability issue more accurately via a sophisticated and global algorithm, the benefits from phase angle measurements of the PMUs.

In load shedding distribution we can also apply the power flow tracing algorithm, to select the more effective load busses and thus reducing the number of load busses in the total power imbalance. The test results indicates that the improvement of load shedding distribution of load shedding method can gives the new steady state of power system in view of frequency stability, voltage stability and load ability, it also a good transient behavior. Thus for the load shedding in particular applications there is a new choice to protect the system safely and efficiently

\section{REFERENCES}

[1] P. Kunduret al., IEEE/CIGRE Joint Task Force on Stability Terms and Definitions, "Definition and classification of power system stability," IEEE Trans. Power Systems, vol. 19, no. 3, pp. 1387-1401, Aug. 2004.

[2] A. P. Ghaleh, M. SanayePasand, and A. Saffarian, "Power system stability enhancement using a new combinational loadshedding algorithm," IET Gen., Transm., Distrib., vol. 5, no. 5, pp. 551-560, May 2011.

[3] A. Saffarian and M. Sanaye-Pasand, "Enhancement of power system stability using adaptive combinational load shedding methods," IEEE Trans. Power Syst., vol. 26, no. 3, pp. 1010-1020, Aug. 2011.

[4] P. M. Anderson and M. Mirheydar, "An adaptive method for setting under frequency load shedding relays," IEEE Trans. Power Syst., vol. 7, no. 2, pp. 647-655, May 1992.
[5] V. V. Terzija, "Adaptive underfrequency load shedding based on the magnitude of the disturbance estimation," IEEE Trans. Power Syst., vol. 21, no. 3, pp. 1260-1266, Aug. 2006.

[6] Z. Zhong, "Power systems frequency dynamic monitoring system design and applications," PhD. dissertation, Dept. Elect.Comput. Eng., Virginia Polytechnic Institute and State Univ., Blacksburg, VA, USA, Jul. 2005.

[7] U.Rudez and R. Mihalic, "Analysis of underfrequency load shedding using a frequency gradient," IEEE Trans. Power Del., vol. 26, no. 2, pp. 565-575, Apr. 2011.

[8] H. Seyedi and M. Sanaye-Pasand, "New centralised adaptive load-shedding algorithms to mitigate power system blackouts," IET Gen., Transm, Distrib. vol.3, no.1, pp.99-114, Jan.2009.

[9] D. Karlsson, M. Hemmingsson, and S. Lindahl, "Wide area system monitoring and control-terminology, phenomena, and solution implementation strategies," IEEE Power and Energy Mag., vol. 2, no. 5, pp. 68-76, Sep.-Oct. 2004.

[10] M. Glavic and T. Van Cutsem, "Wide-area detection of voltage in-stability from synchronized phas or measurements. Part I: Principle," IEEE Trans. Power Syst., vol. 24, no. 3, pp. 14081416, Aug. 2009.

[11] J. De La Ree, V. Centeno, J. S. Thorp, and A. G. Phadke, "Synchrjonized phasor measurement applications in power systems," IEEE Trans. Smart Grid, vol. 1, no. 1, pp. 20-27, Jun. 2010 .

[12] A.G.PhadkeandJ.S.Thorp Synchronized Phasor Measurements and Their Applications. New York, NY, USA: Springer, 2008.

[13] IEEE Standard for Synchrophasor Measurements for Power Systems, IEEE Std. C37.118.1-2011 (Revision of IEEE Std C37.118-2005), Dec.2011.

[14] B. Milosevic and M. Begovic, "Voltage-stability protection and control using a wide-area network of phasor measurements," IEEE Trans. Power Syst., vol. 18, no. 1, pp. 121-127, Feb. 2003.

[15] M. Zima, M. Larsson, P. Korba, C. Rehtanz, and G.Andersson, "Design aspects for wide-area monitoring and control systems," Proc.IEEE, vol. 93, no. 5, pp. 980-996, May 2005 .

[16] J. Bialek, "Topological generation and load distribution factors for supplement charge hallocation in transmission open access," IEEE Trans. Power Syst., vol. 12, no. 3, pp. 1185-1193, Aug. 1997.

[17] B. Zhang, S. Chen, and Z. Yan, Advanced Analysis for Power Network, 2nd ed. Beijing, China: Tsinghua Univ. Press, 2007. 